\title{
Spectrum of gallbladder diseases- A comparative study in North Vs South Indian population
}

\author{
Harendra Kumar', Garima Dundy ${ }^{2, *}$,Hema Kini ${ }^{3}$, Avani Tiwari ${ }^{4}$, Minakshi Bhardwaj ${ }^{5}$ \\ 1,2 Associate Professor, ${ }^{3}$ Professor and Head, ${ }^{4}$ Assistant Professor, ${ }^{\mathbf{5}}$ Senior Consultant, Dept. of Pathology, ${ }^{\mathbf{1}, 2}$ Sarojini Naidu \\ Medical College, Agra, Uttar Pradesh, Kasturba Medical College, Mangalore, Karnataka, Pt. J. N. M. Medical College, Raipur, \\ Chhattisgarh, P.G.I.M.E.R. \& Dr. Ram Manohar Lohia Hospital, New Delhi, India
}

\author{
*Corresponding Author: \\ Email: garima.dundy@gmail.com
}

\begin{abstract}
Introduction: Cholecystectomy specimens are frequently received specimens. The number of cholecystectomy has increased more than $50 \%$ in the last decade, a vast majority performed annually for gallstone related diseases. Present study was done to study the morphological features of cholecystectomy specimens \& to compare the spectrum of gallbladder diseases in both the populations in North Indian as well as South Indian populations.

Materials and Methods: A total 800 cholecystectomy specimens (400 cases each from North India \& South India) were studied at Kasturba Medical College, Mangalore and Postgraduate Institute of Medical Sciences \& Medical Research and associated Dr. Ram Manohar Lohia Hospital, New Delhi.

Results: Gender distribution (M:F) in North India was 1:4.88, whereas in South India it was 1:1.33. Chronic cholecystitis was significantly higher in North Indians (84\%) as compared to South $(66.75 \%)$. Gallbladder carcinoma was more common in North India $(2 \%)$ as compared to South $(1.25 \%)$. Dysplasia associated with cholecystitis was more common in North India (2.50\%) as compared to South $(1.75 \%)$. Associated cholesterolosis was significantly seen in North Indian study group (17.75\%), whereas no case was seen in South.
\end{abstract}

Keywords: Cholecystitis, Metaplasia, Dysplasia, Carcinoma, Gallbladder, Indian population.

\section{Introduction}

Gallbladder is one of the most commonly encountered specimens in thesurgical pathology laboratory. A majority of such specimens show, rather mundane changes associated with chronic cholecystitis, a minority will harbour a highly lethal carcinoma. Often under appreciated, the gallbladder may be affected by a variety of pathological processes that have specific clinical correlates. Reactive changes within cholecystitis may mimic dysplasia. Usual stone associated cholecystitis has only mild inflammation, but variants of cholecystitis may have abundant xanthoma cells, eosinophils or lymphocytes and plasma cells. Metaplasia from normal columnar absorptive epithelium to mucinous epithelium occurs in some case $\&$ a few may progress to dysplasia which is thought to be main precursor of invasive carcinoma. Most invasive carcinomas present at advanced stage \& therefore are highly lethal. Resections of gallbladder performed in such cases must be accurately classified \& staged to provide optimal prognostic information. ${ }^{1,2}$ This study was thus conducted to compare the spectrum of gallbladder diseases in North Indian \& South Indian populations.

\section{Aims and Objectives}

1. To study the morphological features of cholecystectomy specimens in North Indian as well as South Indian population.

2. To ascertain the presence of precursors of dyplasia in gallbladder involved by chronic cholecystitis.

3. To compare the spectrum of gallbladder diseases in both the populations.

\section{Materials and Methods}

In the present study a total 800 cholecystectomy specimens (400 cases each from North \& South Indian population) were studied. Initially 400 cases were studied in the departments of Patholgy, Kasturba Medical College, Mangalore (South Indian population) over five years (from May 2002 to April 2007) and were compared with 400 cases received at Postgraduate Institute of Medical Education \& Research, and associated Dr. Ram Manohar Lohia Hospital, New Delhi (North Indian population), over one year (from January 2009 to December 2009). Detailed history \& other investigations were obtained from records available. H\&E sections were evaluated for spectrum of various gallbladder lesions including metaplasia, dysplasia \& carcinomas, in both the populations. 


\section{Results}

Gender distribution (M:F) in North Indian study group was 1:4.88, whereas in South India it was 1:1.33. Mohan et al $(2005)^{3}$ reported M:F ratio of 1:6.4, while Khanna et al (2006) $)^{4}$ found M:F ratio of 1:4.8 and Baig at al (2002), ${ }^{5}$ 1:2.63. Khanna et al $(2006)^{4}$ reported mean age in North Indian 42.50 years, Mohan et al
$(2005)^{3}$ found that most common age group affected was 31-40 years (Table 1).

Spectrum of various gallbladder diseases and associated lesions, in both the populations are described in Table 2 \& 3.

Table 1: Age distribution

\begin{tabular}{|l|c|c|}
\hline Common mean age & North Indian population & South Indian population \\
\hline Age range & $\begin{array}{c}41.97 \mathrm{yrs} \\
(\mathrm{M}-45.35, \mathrm{~F}-41.35)\end{array}$ & $\begin{array}{c}45.56 \mathrm{yrs} \\
(\mathrm{M}-47.47, \mathrm{~F}-45.87)\end{array}$ \\
\hline $\begin{array}{l}\text { Mean age for } \\
\text { carcinoma }\end{array}$ & 4 months to $82 \mathrm{yrs}$ & $1 \frac{1 / 2 \text { to } 85 \mathrm{yrs}}{51.38 \mathrm{yrs}}$ \\
\hline $\begin{array}{l}\text { Maximum case in age } \\
\text { group }\end{array}$ & $54.50 \mathrm{yrs}$ & $\mathrm{yrs}(28.25 \%)$ followed \\
\hline
\end{tabular}

Table 2: Diagnosis of 400 cases each of North Vs South Indian populations

\begin{tabular}{|l|c|c|c|}
\hline Diagnosis & North Indian population & South Indian population & p-value \\
\hline Chronic cholecystitits & $336(84.00 \%)$ & $267(66.75 \%)$ & 0.001 \\
\hline Acute cholecystitis & $04(1 \%)$ & $24(6 \%)$ & 0.001 \\
\hline Chronic active cholecystitis & $18(4.50 \%)$ & $81(20.25 \%)$ & 0.001 \\
\hline Gangrenous cholecystitis & $01(0.25 \%)$ & $09(2.25 \%)$ & 0.406 \\
\hline $\begin{array}{l}\text { Xanthogranulomatous } \\
\text { cholecystitis }\end{array}$ & $29(7.25 \%)$ & $02(0.50 \%)$ & 0.001 \\
\hline $\begin{array}{l}\text { Chronic Follicular } \\
\text { cholecystitis }\end{array}$ & $01(0.25 \%)$ & 00 & 0.001 \\
\hline Choledochal cyst & $01(0.25 \%)$ & $01(0.25 \%)$ & 1.00 \\
\hline Adenocarcinoma & $8(2 \%)$ & $5(1.25 \%)$ & 0.080 \\
\hline Bile duct atresia & $1(0.25 \%)$ & 00 & 0.001 \\
\hline Empyema & 00 & $4(2 \%)$ & 0.0045 \\
\hline Mucocele & $1(0.25 \%)$ & $1(0.25 \%)$ & 1.00 \\
\hline Autolysed Gallbllader & 00 & $1(0.25 \%)$ & 0.001 \\
\hline Normal Gallbllader & 00 & $5(1.25 \%)$ & 0.0249 \\
\hline Total & 400 & 400 & \\
\hline
\end{tabular}

Tab 3: Associated gallbllader lesions

\begin{tabular}{|l|c|c|}
\hline Stones & North Indian population & South India population \\
\hline Cholesterolosis & $\begin{array}{c}382 / 400(95.5 \%) \\
\text { (M 62, F 320) }\end{array}$ & $\begin{array}{c}321 / 400(80.25 \%) \\
\text { (M172, F 228) }\end{array}$ \\
\hline Hyperplasia & $71(17.75 \%)$ & 00 \\
\hline Metaplasia- & $140 / 400(35.00 \%)$ & $126 / 400(31.50 \%)$ \\
1. Pyloric & $96 / 400(24 \%)$ & $95 / 400(23.75 \%)$ \\
2. Intestinal & $87(21.75 \%)$ & $79(19.75 \%)$ \\
3.Combined & $8(02 \%)$ & $11(2.75 \%)$ \\
3. Squamous & 0 & $3(0.50 \%)$ \\
4. Chondroid & 0 & $0.75 \%)$ \\
\hline Dysplasia ( low Grade) & $1(0.25 \%)$ & $7(1.75 \%)$ \\
\hline
\end{tabular}




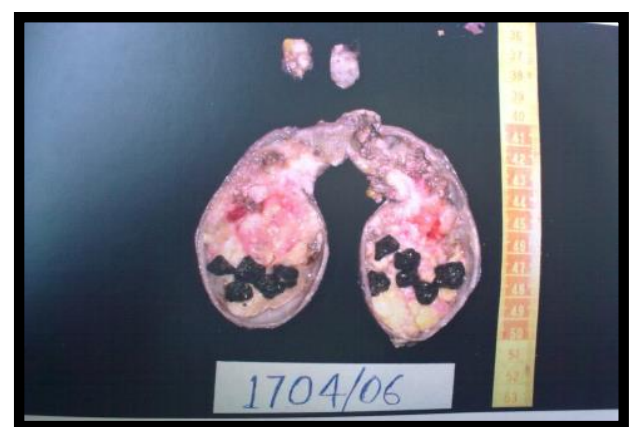

Fig 1: Specimen of carcinoma gallbladder with intraluminal growth $\&$ multiple pigment stones

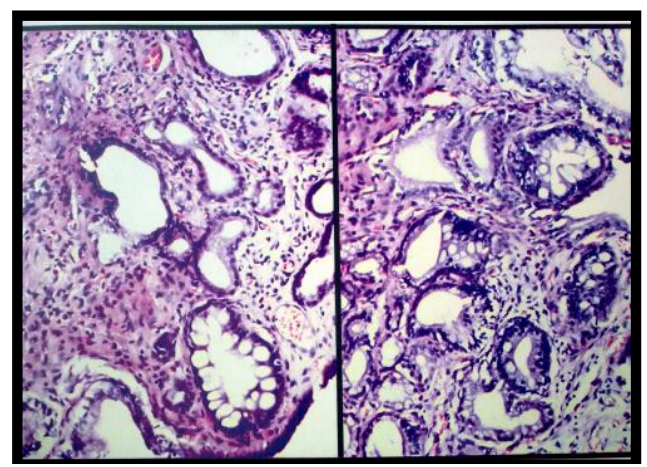

Fig 2: Chronic cholecystitis with intestinal metaplasia (400X, H\&E)

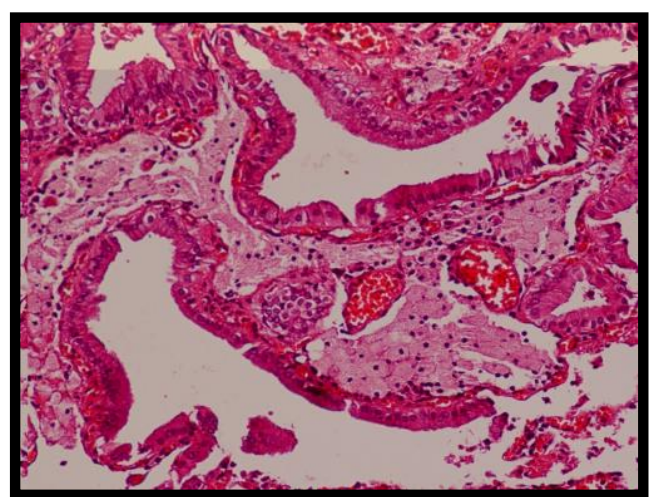

Fig 3: Cholesterolosis (400X, H\&E)

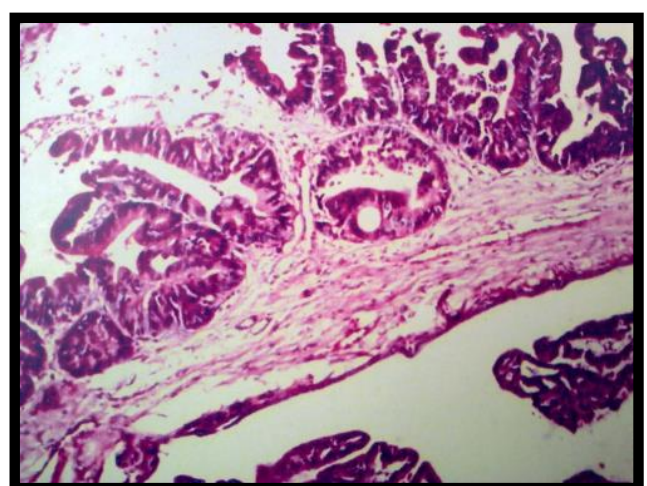

Fig 4: Invasive adenocarcinoma of gallbladder (100X, H\&E)

\section{Discussion}

Inflammatory diseases of gallbladder are a frequent cause of morbidity in west. The term cholecystitis encompasses a group of disorders that differ in their pathologic, pathogenetic and clinical characterstics. Most inflammatory diseases of gallbladder show nonspecific histologic features in that they elicit non distinctive types of cellular infiltrate. However, characterization of inflammatory patterns helps the pathologist to establish a diagnosis and provides insight into the pathogenesis of a disease. ${ }^{6}$

The $1^{\text {st }}$ discussion of gallstones as "dried up humors concreted as stones" is ascribed to the Greek physician, Alexander of Tralles ( $5^{\text {th }}$ century A.D.). The $14^{\text {th }}$ century physician, Gentile da Foligno, suggested for the $1^{\text {st }}$ time the relationship of cholecystitis \& gallstones based on autopsy findings. Gallstones were removed from a living patient for the $1^{\text {st }}$ time in 1618 by German surgeon, Wilhelm Fabry. First sucessful cholecystectomy was done by Carl Langenbuch in $1882.6,7$

Mohan et al $(2005)^{3}$ reported estimated prevalence of gallstones in India as $2 \%$ to $29 \%$. In India, this disease is around seven times more common in North India (stone belt) than in South India. Unisa $\mathrm{S}$ et al $(2011)^{8}$ population-based study to estimate prevalence and determine risk factors of gallbladder diseases in the rural Gangetic basin of North Indi revealed a prevalence of GBD of $6.20 \%$. In present study, we found a significant difference in prevalence of gallbladder diseases (tab 2) in two studied populations (five times more common in North India). Associated gallbladder lesions including gallstones, hyperplasias, metaplasia, dysplasia \& cholesterolosis are discussed in Table 3. Dietary differences in the two regions are suspected to be responsible for the difference in prevalence rate. Sex hormones and sedentary habits of most women in India expose them to factors that possibly promote the formation of gallstones. Gender distribution (M:F) in North India was 1:4.88, whereas in South India it was 1:1.33. Mohan et al (2005) $)^{3}$ reported M:F ratio of 1:6.4, while Khanna et al $(2006)^{4}$ found M:F ratio of 1:4.8 and Baig at al (2002) $)^{5}, 1: 2.63$. Increase in the prevalence of gallstones with the age probably because of decrease in activity of alpha reductase, and an increase in activity of HMG CoA reductase resulting in an increased cholesterol secretion $\&$ saturation of bile. Shukla et al ${ }^{10}$ and Usha \& Gupta ${ }^{11}$ reported that, the average age of these patients in India is a decade younger than those in the west. The reported incidence of gallbladder carcinoma (GBC) in India varies from 4.4- $12.4 \%$ It is upto 10 times more frequent in North India as compared to South India. Eastern Uttar Pradesh and Indo Gangetic belt is amongst the highest incidence of GBC in the world along with Chile \& Bolivia. Dominant lithogenic genes are now suspected based the studies from North 
America which had showed that gallstone associated diseases are more common in migrants from Asia. The relationship of gallstones to carcinoma was assumed to be due to chronic stimulation leading to mucosal metaplasia which may occasionally or rarely, eventually lead to development of carcinoma.

\section{Conclusion}

In present study, gallbladder diseases are five times more common in North Indian population as compared to South. ${ }^{12} \mathrm{M}: \mathrm{F}$ ratio was $1: 4.88$ in North Indians as compared to $1: 1.33$ in South Indians. Mean age was lower in North Indian population. Acute cholecystitis, acute on chronic cholecystitis \& gangrenous cholecystitis were significantly higher in South Indian population as compared to North Indians. Chronic cholecystitis was significantly higher in North Indians (84\%) as compared to South $(66.75 \%)$. Gallbladder carcinoma (Fig 1 \& 4) was more common in North Indians (2\%) as compared to South $(1.25 \%)$. Dysplasia associated with cholecystitis (Table 3) was more common in North India (2.50\%) as compared to South $(1.75 \%)$. Associated cholesterolosis (Table 3\& Fig 3) was significantly seen in North Indian study group $(17.75 \%)$, whereas no case was seen in South Indian population studied.

All the patients with symptomatic gallbladder diseases undergoing excision of gallbladder must have the benefit of a thorough histopathological examination of the specimen to confirm a benign diagnosis, if any; to detect precursors to carcinoma in long standing cases $\&$ have a thorough assessment of type \& extent of disease in case of malignancy. Therefore, care must be taken to ensure adequate and immediate fixation of the specimen by the surgeon accompanied by meticulous gross and microscopic evaluation by the pathologist.

\section{References}

1. Adsay MV. Gallbladder, extrahepatic biliary tree and ampulla. In: Mills SE. Sternberg's diagnostic surgical pathology. 4ed. Philadelphia: Lippincott Willium and Wilkins, 2004:1175-1828.

2. Hansel DE, Maitra A, argani P. Pathology of the gallbladder: a concise review. Curr Diag Pathol 2000;10:304-17.

3. Mohan H, Punia RPS, Dhawan SB, Ahal S, Sekhon MS. Morphological spectrum of gallbstone disease in 1100 cholecystectomies in North India. Indian J Surg 2005;67:140-42.

4. Khanna R, Chasuria R, Kumar M, Shukla MS. Histological changes in gallbladder due to stone diseases. Indian J surg 2006;68:201-04.

5. Baig SJ, Biswas S, Das S, Basu K, Chattopadhyay G. Histopathological changes in gallbladder mucosa in cholelithiasis. Trop Gastroenterol 2002;23(1):25-27.

6. Jessurun J, Pambuccian S. Infections and inflammatory disorders of the gallbladder and extrabilliary tract. In: Odze RD, Goldblum JR, Crawford JM. Surgical
Pathology of GI tract, Liver, Billiary tract and Pancreas. Philadelphia; Saunders, 2004:609-638.

7. Lack EE. Pathology of Pancreas, Gallbladder, Extrahepatic biliary tract and Ampullary region. New York: Oxford University press; 2003:465-502.

8. Unisa S, Jagannath P, Dhir V, Khandelwal C, Sarangi, L, Roy TK. Population-based study to estimate prevalence and determine risk factors of gallbladder diseases in the rural Gangetic basin of North India. HPB (Oxford). 2011;13(2):117-125.

9. Barakat J, Dunkelberg J, Ma T. Changing patterns of gallbladder carcinoma in Neww Mexico. Cancer 2006; 106 (2):434-40.

10. Shukla HS, Awasthi K, Naithani YP, Gupta SC. A clinicopathological study og gallbladder cancer. Ind J Cancer 1981;13:196-201.

11. Usha, Gupta S. Mucosal metaplasia in cholecystitis and carcinoma of the gallbladder. Ind J Pathol Microbiol 1990;33:92-95.

12. Kumar H, Kini H, Tiwari A. Histological evaluation of 400 cholecystectomy specimens. Journal of Pathology of Nepal 2015;5(10):834-40. 